\title{
Translanguaging engagement: Dynamic multilingualism and university language engagement programmes
}

\author{
Jessica Bradley \\ Leeds Trinity University
}

(Text received August 5 2017; accepted September 30 2017)

DOI: https://doi.org/10.5565/rev/jt13.759

\begin{abstract}
This thought piece reflects on the implications of the author's research on translanguaging for university language engagement work with children and young people in schools and colleges. It presents the LangScape Curators project as an example of possible directions for research and practice in this area.
\end{abstract}

Key words: Translanguaging, engagement, modern languages and cultures, multilingualism, education

\section{Introduction}

This article takes the form of a thought piece (Ding, 2016). Its purpose is to consider the possibilities of my current research, which focuses on dynamic multilingualism and multimodality in community arts, when applied to the broad area of university language engagement with children and young people in schools and colleges. Writing a thought piece of this kind has a number of purposes. It aims to develop and articulate an evolving dialogue between my current research and my previous higher education practice in educational engagement for languages and arts. In so doing I start to sketch out the implications of my research within the broader arena of languages and cultures, and particularly in terms of engagement with these subjects in schools and colleges. It brings into contact translanguaging (e.g. García \& Li Wei, 2014; Otheguy, García, \& Reid, 2015; MacSwan, 2017) as one particular lens for understanding dynamic multilingualism, empirical evidence drawn from an ethnographic research project with multilingual street artists, and university languages engagement work with schools and colleges. I consider a current example of research-led engagement work, LangScape Curators (Atkinson \& Bradley, 2017; Bradley, Moore, Simpson, \& Atkinson, 2018), to sketch out possible directions for research and practice in this area.

As a thought piece it is also unfinished. It is a starting point. It sets out a number of questions, ones which I will continue to ask and to find answers to over the course of the next few years. Questions that will also - I know - lead to more questions. But it is also an attempt 
to draw together threads from a series of projects - research and practice-based - and articulate the commonalities between them. The anthropologist Tim Ingold has developed a taxonomy of lines, in which he writes about threads and traces. A thread, he explains, is "a filament of some kind, which may be entangled with other threads or suspended between points in three-dimensional space" (2016/2007, p. 42). A trace is "any enduring mark left in or on a solid surface by a continuous movement" (p. 44). Writing - and in this case, bringing together multiple, diverse, often conflicting, threads of research and practice - is a deliberate act of meaning making. As Ingold explains, these threads can also become traces and traces can become threads. In doing so, I hope that some of these threads will become traces, or, enduring marks. And some of the traces will become threads, entangled together into new ideas.

The meshwork is a concept Ingold borrows from Henri Lefebvre (Lefebvre, 1991/1974, pp. 117-18; Ingold, 2016/2007, p. 84) to describe the 'entanglement of lines' (ibid). For Ingold, these lines are 'the trails along which life is lived' (ibid). The meshwork provides a useful metaphor for a doctoral research project and the thesis writing process as a deliberate articulation of the meshwork. I start by describing my current research project, as one entanglement or meshwork of threads. Here I am situating this research within the broader context of my previous professional practice in languages and arts engagement, setting out the traces of my previous practice and my current research. These are put into dialogue, giving examples from my research and from my practice. I draw out research findings which illustrate the elements which link both the research and languages engagement practice. The purpose of sketching out a number of ideas for continuing this work and establishing a research agenda, in turn, aims to mark out a trace (an enduring trace [Ingold, 2016/2007, p.75], I hope).

\section{Research context: Translanguaging in superdiverse city wards}

For my research I am attached to the Arts and Humanities Research Council-funded project 'Translation and Translanguaging: Investigating Linguistic and Cultural Transformations in Superdiverse Wards in Four UK Cities' (TLANG, PI Angela Creese, University of Birmingham $)^{\text {ii }}$. This is a four-year project which investigates communication across four UK cities (Birmingham, Cardiff, Leeds and London) in four areas (Business, Heritage, Sport and Law). Broadly this project seeks to understand how people draw from multilingual repertoires in non-educational contexts. As it draws to a close, we can take stock of what we have done 
and start to map out the directions (or threads) in which the research has taken us and our developing understandings of translanguaging (as traces).

At a local level, the Leeds case study, which I have been part of, has focused on the Gipton and Harehills ward of the city, and the neighbourhoods of Chapeltown and Burley. The team have worked across different contexts including advocacy and advice drop-in sessions for recently arrived people from EU accession countries, an emergent community interest company providing heritage activities for the Czech and Slovak communities, an amateur basketball team, a capoeira group, and an immigration advice service. The research across these diverse spaces and places has challenged the initial understandings of translanguaging we had at the start of the project in 2014.

The project itself is a meshwork made of multiple interwoven threads and traces. Over the course of the research, we have considered translanguaging spaces (Li Wei, 2011; García and Li Wei, 2014; Blackledge \& Creese, 2017; Zhu Hua, Li Wei, \& Lyons, 2017) as positive and negative in the context of a start-up community interest company and how spaces for dynamic multilingualism are opened up and closed down (Bradley \& Simpson, forthcoming). This has been extended to ESOL (Simpson \& Bradley, 2017), with James Simpson and Mel Cooke developing translanguaging as pedagogy for English language classrooms (Cooke \& Simpson, 2017), asking what a multilingual approach to English learning for adult migrants might look like. We have conducted detailed multimodal analyses of translanguaging and embodiment in the context of sports clubs in terms of distributed cognition in basketball training (Callaghan, Moore, \& Simpson, 2018). We have broadened our scope to encompass the visual, using arts-based methods and collage as a way of considering how visual arts and literacy might be used to open up translanguaging spaces for creativity and criticality in language and in transdisciplinary pedagogy (Atkinson \& Bradley, 2017; Bradley, Moore, Simpson, \& Atkinson, 2018). The materiality of translanguaging, and the objects and props created by artists for street arts production has been explored alongside and in connection with the transmodality of spoken word poetry and musical adaptation. Threads have been drawn, connecting these discrete projects (Bradley \& Moore, forthcoming). Continuing in the arts-based arena, translanguaging was analysed visually in the silk paintings created by refugees in a co-produced project stemming from the TLANG work for the Connected Communities Utopias 2016 festival (McKay \& Bradley, 2016). Building on the translation classifications used by Roman Jakobson as intralingual, interlingual and intersemiotic (Baynham, Bradley, Callaghan, Hanusova, \& Simpson, 2015, p. 19) we developed the 
concept of interdiscursive translanguaging $(2015, \mathrm{p} .53)$ as a way of framing the negotiation of unfamiliar discourses (Baynham \& Hanusova, 2017).

The purpose of setting out these multiple and divergent directions in the paragraph above is to demonstrate how a concept of this kind, a fairly recent concept, is taken up in different and multiple ways, even within a small, interdisciplinary research team working at a local level.

Ricardo Otheguy and colleagues describe translanguaging as: "the deployment of a speaker's full linguistic repertoire without regard for watchful adherence to the socially and politically defined boundaries of named (and usually national and state) languages" (Otheguy et al., 2015, p. 281). Translanguaging as a term was originally coined by Cen Williams in 1994 to describe language alternating practices in bilingual schools in Wales (García \& Li Wei, 2014). It was taken up by linguists (e.g. Blackledge \& Creese, 2010; García, 2009; García \& Li Wei, 2014) seeking to develop ways of understanding flexible and fluid multilingualism and its application in education. Translanguaging is one of multiple approaches to dynamic multilingual practice - a 'school' Alastair Pennycook (2017) describes as the 'trans-super-poly-metro movement'. It is beyond the scope of this article to offer a critique of translanguaging and multiple other ways of conceptualising dynamic multilingualism, suffice to say it is a contested notion (see Jaspers [2017, p. 3], for whom the "profusion of meaning gives reason for concern"). Alternative concepts include polylanguaging (Jorgenson, 2003); code-meshing (Canagarajah, 2011); translingual practice (Canagarajah, 2013), metrolingualism (Otsuji \& Pennycook, 2010; Pennycook \& Otsuji, 2015) and plurilingualism (Lüdi \& Py, 2009). Translanguaging is also a creative lens. It has been a catalyst for thinking more broadly about communication, both in terms of the individual idiolect (Otheguy et al., 2015) and what Sandrine Eschenauer (2014) describes as translangageance, or the development of a shared language, following Joëlle Aden who describes translanguaging as 'l'acte dynamique de reliance à soi, aux autres et à l'environnement par lequel emergent en permanence des sens partagés entre les humains" (Aden, 2013, p. 115, in Eschenauer, 2014, p. 7). For Aden's definition, the concept of shared space is central. 


\section{Translation and translanguaging in production and performance in community arts}

For my own research I investigate how people make meaning across space and place in multilingual street arts projects (see Bradley, 2017; Bradley \& Moore, forthcoming). I draw from a range of approaches, including linguistic and visual ethnography (Blommaert \& Jie, 2010; Copland \& Creese, 2015; Pink, 2014) and from multimodality (Kress \& van Leeuwen, 1996; 2001; Rowsell, 2012; Jewitt, Bezemer, \& O’Halloran, 2016). In this sense I am developing links between quite different paradigms. Multimodal approaches to communication developed from Hallidayan systemic function linguistics (Halliday, 1978), with linguistic ethnography having developed from the ethnography of communication and interactional sociolinguistics (Gumperz, 1982; Hymes, 1972, 1974). These are not easily reconciled (Pink, 2011) with anthropological and multimodal approaches having quite different theoretical and methodological frameworks. Yet, as Sarah Pink (2011, p. 275) states, scholars are engaging with media, and combining methods to address key anthropological questions and therefore innovative approaches which draw coherently from across disciplines are necessary and possible. Put simply, communication in social life is complex. So any approach to researching and understanding communication must account for this complexity. For my research I have, therefore, assembled a contingent (Kress, 2011, p. 240) meshwork of theories and methodologies as the 'toolkit' for my research (see also Adami, 2017, who sets out an innovative agenda for multimodality and superdiversity). In this way I demonstrate not what different theories can do for the same data as different lenses. Instead, I seek to articulate that ethnographic approaches to my research and attention to multimodality in my research were necessary to answer the research questions, and that obtaining complementary materials for analysis (Kress, 2011, p. 240), for example photographs and visual data, was a core methodological and epistemological consideration.

My research in the context of community arts asks how people communicate across languages and cultures in collaborative processes of production and performance. I worked with a UK-based arts organisation and a Slovenia-based arts organisation as they collaborated to devise and produce a street theatre production, 'How Much Is Enough' based on the traditional folk story of the Zlatorog, or golden-horned goat (Copeland, 1933). During the five-month period in which I worked with the group, I spent time observing the workshops and processes and participating in them at various points. I frame this within what Sarah Pink and Jennie Morgan (2013) describe as short-term ethnography. Five months is a short time in 
which to conduct ethnographic research and this core data collection period took place within a broader commitment to working with the group for a longer time and to developing collaborative projects linking from the TLANG project and from our shared research questions.

I use the concept of translanguaging as a starting point for my research into multilingual and multimodal communication. My research builds on the current scholarship developing around translanguaging's multimodal affordances, including by Adrian Blackledge and Angela Creese (2017) who focus on the "corporeal dimension of translanguaging" (p. 250) and develop the concept of semiotic repertoires (see also, Kusters, Spotti, Swanwick, \& Tapio, 2017; Pennycook, 2017). In adopting a multimodal approach, I decentre 'language' as a central concern for my research (MacLure, 2013) and incorporate the visual and the material, including the props and the puppets that are found and made during a street arts production process, extending its scope to the objects and, in particular, the puppets. In doing so, I establish translanguaging as both the focus for the research (how do people translanguage during processes of production and performance?) but also as epistemology (Moore, Bradley, \& Simpson, forthcoming) (how is translanguaging also a new way of understanding knowledge production, drawing from across research approaches and paradigms?). I also question where the limits of a particular concept might lie. What happens when the boundaries of a particular theoretical concept are extended? What is lost and what is gained?

My research findings are centred on four main stages of the production of a piece of street theatre. I have called these stages conceptualisation, making, devising and performing. The folk story on which the production is based travels across these stages and undergoes a series of multiple resemiotisations (Iedema, 2001, 2003) until it is performed in the street as part of an international street arts festival. The four stages are sketched out here. Firstly, the introduction of the story and the basis for the street arts production takes place during puppetry training workshops which I frame as conceptualisation and for which narrative is the central analytical focus. Secondly, the text becomes a synopsis, a 'promo', objects, puppets, costumes and props. In this making stage the analysis shifts to foreground the objects as they are created and the historical bodies (Scollon \& Scollon, 2004) imbued within them. Each object, each puppet, each choice of prop, of costume, of accessory, affects the development of the production. As Catherine Kell puts it, "things make people happen" (2015, p. 423). Thirdly, in the devising stage, the actors work together to create a performance. The focus here is on interactional data and decisions made across the workshops in which the production 
was worked and reworked into its final version. Fourthly, during the performance stage, the production itself forms the focus of analysis. The performance is brought into being across the streets and squares of Slovenia for an international street arts festival, pulled out of suitcases and then hidden away in side alleys. As an interactional piece, it represents and embodies the actions, objects, people, histories and conflicts that have built it. It is, in itself, a contact zone (Pratt, 1991).

My main research findings focus on the concept of the translanguaging space and the ways in which these spaces develop and recede in unexpected ways. Zhu Hua and colleagues (Zhu Hua et al., 2017, p. 412) define the translanguaging space as one in which "various semiotic resources and repertoires, from multilingual to multisensory and multimodal ones, interact and co-produce new meanings". Drawing on this broad definition, spaces of production and performance, as sites of interaction and co-production leading to new meanings, could be framed as translanguaging spaces. The semiotic resources and repertoires of the actors are brought together and drawn upon with the aim of producing a piece of street theatre - a new meaning, to use the words of Hua and colleagues. But the data demonstrate that even in these spaces of creativity and criticality, boundaries and restrictions are imposed. Actors are invited to draw on their full communicative repertoire as ideas are gathered together and explored. However at certain moments and for certain periods of time the language spoken must be English. For example, during the sharing of stories in the conceptualisation stage, the workshop leader asks that these stories be told in English, therefore removing the possibilities for multilingual story telling. Yet, translanguaging spaces continue to emerge and the actors creatively play with words from multiple 'named languages' (or Languages). At the same time, the actors do not display "watchful adherence" to what Otheguy and colleagues describe as "the socially and politically defined boundaries of named (and usually national and state) languages" (Otheguy et al., 2015, p. 281) during the workshops, instead disrupting and playing with these norms.

During the making stage, language is decentred as the props and objects that are created by the group disrupt the initial plan for the performance (Bradley, 2015). Metacommentary (Rymes, 2013; Creese, Takhi, \& Blackledge, 2014) on language takes place in spaces betwixt and between the main activity. The devising stage requires negotiation across practices. Languages, or named and bounded Languages (Blommaert, 2013) become less important during the production process. Instead, the focus is on how the text - the story - can be made into a performance in the street, to be communicated to a wide audience with as little verbal communication within it as possible. 
Therefore, throughout the development of the street arts production, language is both centred and decentred. Scripts are drafted and redrafted. Objects are adapted. The script is returned to continuously, and the new objects being created are considered in its redrafting, in its editing, and in its application.

The street arts performance itself is the final resemiotisation of the text, the resultant meshwork of threads. However, discussion of named Languages is part of the final devising process for the performance: which Language(s) should the performers use for the play's dialogue? Translanguaging is evident within the performance, which is a multilingual piece, however the boundaries are clearly demarcated between named Languages: English, Slovene and Italian, leading to questions of to what extent named and bounded Languages can be bypassed. To what extent can a performance, in the street, represent the nuances and playfulness of the processes of production and of communication in social settings, in translanguaging spaces?

In summary, my research sets out an analysis of the possibilities and impossibilities of translanguaging spaces. It establishes how language, and the concept of Language, are used in community arts contexts: as a creative tool, as a marker of sameness and difference, as an object of play. But also how, even within a space which ostensibly encourages the deployment of an individual's full communicative repertoire, and its extension, Language continues to constrain and restrict.

\section{Languages engagement}

The previous sections set out a short description of the translanguaging research stemming from the Leeds-based TLANG project and my own related research. There are a number of directions for its possible application across multiple contexts. Here I want to consider the broad arena of university languages engagement programmes with schools and colleges. Prior to starting my research I worked for almost a decade in the area of languages (and arts) engagement in higher education. I developed multiple projects and initiatives working with schools and colleges to address the continuing decline in language take-up at Key Stage 4, Key Stage 5 and in higher education, including for the HEFCE-funded national project 'Routes into Languages, ${ }^{\text {,iii }}$. At the time that I started the role (2005) the decline in numbers taking languages such as French and Spanish was continuing sharply following the implementation of curriculum reforms in 2004 that led to languages being made optional in many schools at Key Stage 4 (Lanvers, 2011). Subsequent annual Language Trends surveys 
by the British Council ${ }^{\text {iv }}$ map out the changes each year to the numbers of children and young people taking languages at each stage. Subsequent annual press coverage of GCSE and A Level results invariably includes articles decrying the UK's lack of linguistic skills and the 'language learning crisis' (see Lanvers \& Coleman, 2017 for a critical analysis).

Language learning in schools and universities has, in terms of numbers, been in decline for the past two decades. Ursula Lanvers and James Coleman state that the UK's language skills are considered the lowest in Europe (2017, p. 3). Programmes of activities in languages engagement are developed to address both this drop in numbers actually taking qualifications in languages across educational stages and the social inequalities within this system. According to Lanvers and Coleman (2007, p. 3), statistics demonstrate that schools with higher percentages of pupils eligible for free school meals have a reduced take-up of languages. In this way, university language schools and departments have faced and continue to face challenges in terms of recruitment to language courses, and in terms of widening participation and social justice. As a practitioner working in this area, I found myself questioning evaluative processes for this work, which, at times mainly focused on questionnaire-based responses and quantitative data. It was challenging to track what kinds of effects the engagement programmes were having, both on a short-term basis and longitudinally. 'Attainment-raising' activities were arguably easier to track than those which aimed to be 'aspiration-raising'. I wondered how research into language take-up at school and university could be brought into closer dialogue with engagement practice. In this sense, to what extent could we, as practitioners and researchers in languages, consider engagement work to be theory-generating research and develop methodologies and epistemologies that would both encompass the practice itself as engagement and develop empirical evidence for what works and why it works? Interestingly, similar arguments about developing a robust evidence base for widening participation activities are being set out by Higher Education Funding Council for England (HEFCE), for example for its National Collaborative Outreach Partnership (NCOP) programme ${ }^{\mathrm{v}}$.

There are, of course, wider and very current reasons for 'saving languages'. In October 2016 the All Party Parliamentary Group (APPG) on Modern Languages published a checklist for the UK Government on 'Languages and Brexit', which highlighted the need for languages strategy during the government's preparations to leave the $\mathrm{EU}^{\mathrm{vi}}$ the fear being that the UK will have insufficient linguists for the processes and negotiations themselves and for the post-EU future of the country. 'Brexit', of course, is a broad and highly complex issue which I do not intend address here. Needless to say however, those active in languages 
engagement are considering to what extent attitudes to languages and multilingualism and the country's decision to leave the EU are co-implicated. The possibilities and affordances of languages, as a field, as a subject area, as a discipline, at this time, however, are wide open. As Charles Forsdick (2007, final para.) states, "Research in modern languages is increasingly proving itself to be intellectually vibrant, positioned at the forefront of the arts and humanities, and - perhaps most significant - capable of playing a crucial role in society at a time of national uncertainty". The question is, therefore, how pathways can be developed for intellectually vibrant modern languages research to develop towards programmes of languages engagement with children and young people.

\section{Translanguaging approaches in languages engagement programmes}

In June 2017, Stephen Hutchings and Yaron Matras at the University of Manchester described the current situation for languages in higher education as 'incrementally run down'. In what could be taken as a translanguaging approach to research and teaching in languages departments in the UK, they suggest:

Any reform programme should begin with a rejection of the prevailing compartmentalised, nation-state approach to the organisations of Modern Languages units and curricula. It must recognise that established national boundaries and identities are being eroded and reconfigured by new communications technologies, migration trends, the increasingly multilingual nature of urban environments, and the transnational flows of culture, finance and ideology, generated by a globalised world. (Hutchings \& Matras, 2017, para. 2, emphases added)

It is not within the scope of this article (or indeed my broader intention) to make recommendations for mass restructuring of language departments across the UK to follow the erosion and reconfiguration of national boundaries and identities that these authors describe. In both working in and researching this area over the past thirteen years, I have experienced the ways in which higher education schools and departments of modern languages can respond ably and quickly to changing landscapes (see, for example, the developing dialogue with languages teachers around the new A Level syllabi taking place at the University of Leeds ${ }^{\mathrm{vii}}$ ) as well as the commitment of university colleagues to programmes of educational engagement. However, what is becoming increasingly interesting to me from the perspective 
of translanguaging - from the findings from my research with artists, as well as from the broader findings of the TLANG project - is how new understandings around dynamic multilingualism (Pennycook's aforementioned 'trans-super-poly-metro movement' which includes translanguaging) are developing in modern languages departments and schools, across from applied linguistics and sociolinguistics (which are often housed institutionally in the UK within schools of education). And, importantly and excitingly, dialogue is taking place about how these understandings might continue to develop across contexts. The Arts and Humanities Research Council's Open World Research Initiative (OWRI) has invested strongly (to the tune of $£ 16$ million) in projects which seek to demonstrate the role of languages in today's increasingly globalised world ${ }^{\text {vii }}$. These include the 'Creative Multilingualism' project, the 'Multilingualism: Empowering Individuals, Transforming Societies (MEITS) project, the 'Cross-Language Dynamics: Reshaping Community' Project and the 'Language Acts and World Making' project. Interestingly, all seek to develop inter-, multi- and trans-disciplinary approaches to language. The MEITS project, as an example, is designed across six strands, ranging from the arts, foreign language learning and cognition. The Multilingual Manchester project, led by Matras, is another example of a project embedding transdisciplinary approaches to language. These large-scale projects demonstrate the growing dialogue between and among 'linguists' (applied, socio, modern, inter alia) that mirrors the kinds of questions my research has raised (for me) in terms of my previous practice. Hutchings and Matras (2017) refer to the dialectic between the intellectualisation of these challenges (similarly to the ongoing discussions of international/home student categories as 'borders', see also Badwan, 2015; Harvey, 2016; Collins, 2017) and the institutional structures within which these discussions take place. We can, following Sinfree Makoni and Alastair Pennycook (2007) challenge the very notion of a 'language' through our research. But, as Chris Perriam (2017) points out, we still conduct our research and are positioned with departments, schools and faculties whose names reflect nation-states and national boundaries. Likewise happens in schools and colleges, with these operating in an even less flexible environment than higher education institutions. Are we equipped, as Hutchings and Matras (2017) suggest, to develop ways of engaging with children and young people in languages that reflect their realities? For example, these ways might include considering and responding to the languages of migrant and diaspora communities in the UK. How can we, in university modern languages schools and departments and in schools of education, work with schools and colleges to co-produce and co-create language curricula in a way which might revitalise languages at all levels in the UK education system? How does 
shifting focus from 'bounded languages' actually work in the context of languages engagement? How do we avoid 'throwing the baby out with the bath water'? How might translanguaging, as a conceptual framework but also as a way of understanding how engagement might work, be a central consideration for languages engagement? To the extent that we can do this at a project level (the TLANG project is multi-disciplinary and this has been one of its strengths, see Blackledge \& Creese et al., 2017), is it also possible to do this at departmental, school and faculty level? Or do we continuously create meshworks, the threads of which intersect high above our own day-to-day work in our institutions?

\section{Translanguaging Arts and Languages Engagement: LangScape Curators}

The focus for this article is languages engagement and I want to now sketch out a few ideas (traces) for a research and practice agenda around translanguaging and languages engagement. These ideas draw from a small-scale educational engagement project, LangScape Curators ${ }^{\text {ix }}$ which uses the linguistic landscape (Blommaert, 2013; Gorter \& Cenoz, 2015; Pennycook, 2017), alongside developing methodologies used by researchers to investigate it, as a lens for children and young people to develop critical and analytical skills, and to understand more about language and communication. The landscape is considered following Gorter and Cenoz, as a "multilingual and multimodal repertoire" (2015, p. 17, in Pennycook, 2017, p. 270) and the approach which is adopted seeks to develop "a holistic view that goes beyond the analysis of individual signs as monolingual or multilingual" (Gorter \& Cenoz, 2015, p. 63).

Earlier in 2017 I was invited to deliver two lectures for Level One undergraduate students in the School of Education at the University of Leeds as part of the 'Education in a Multilingual World' module. For the first of these I focused on the concept of translanguaging and theories of dynamic multilingualism. I drew on research by Brigitta Busch (2016) on biographical approaches to understanding the linguistic repertoire and students were asked to draw a portrait which showed the languages within their repertoire and position these on the portrait. It is an exercise that we have developed and used in engagement activities from the TLANG project when working with children and young people in the Harehills and Beeston areas of Leeds (Atkinson \& Bradley, 2017). The aim of this exercise was to ask students to question the idea of the 'monolingual speaker' and to consider their own communicative repertoires (or idiolects) and the shared aspects of these. The kinds of conversations which arose from this activity included a number of students articulating their concern over not 
being multilingual 'enough', some critique of the language experiences of some of the students in school, discussion over the role of 'English' and language ideologies and nation states. It was a simple exercise requiring a pen, a piece of paper, and drawing. The act of drawing, rather than listing the languages spoken, required the students to think differently, as well as to reflect on where they might position these languages on their bodies and why.

During the school half term holidays in 2016-2017, young people from Leeds-based educational centres in the east and south of the city, carried out a similar exercise but with larger, life-sized portraits which worked to demonstrate the shared elements of our communicative repertoires (for a fuller analysis, see Atkinson \& Bradley, 2017 and Bradley et al., 2018). This was part of a three-day programme of language and arts engagement work for LangScape Curators supported by the university's educational engagement social sciences cluster, based on TLANG research into the linguistic landscape. The young people talked about emoji, about the language of different subjects at school, about text speak, instagram, social media, Facebook messenger. What was particularly striking was the unproblematic way that these (complex, as we researchers thought) ideas about multimodality were considered by the young people, for example in the case of emoji (is emoji a language?, we asked - of course!, was the reply). The linguistic landscape forms the central focus for this programme of activity which has extended to work with undergraduate students and postgraduate researchers through a student education enhancement project (The Out There Challenge, Faculty of Arts and Humanities, 2017) and to a linguistic landscape themed exhibition for the Annual Meeting of the British Association for Applied Linguistics (August-September 2017, University of Leeds).

\section{Translanguaging Approaches to Engagement?}

The overarching aim here is to see dynamic multilingualism as normal and unremarkable (García, 2009). By considering the broad, multilingual, multisemiotic repertoires from an individual and from a shared perspective, we aimed to create spaces in which all participants could draw from their full communicative repertoires and talk about 'language' across contexts. These were spaces of creativity and of criticality in which the young people were able to share their linguistic repertoires and in which we all became co-learners. Over the course of the three days, the young people researched the linguistic landscapes of their communities and synthesised and analysed their findings using a range of arts-based methods, working with artists and researchers. At the end of the three days the participants presented 
their findings at an exhibition to which their parents, carers were invited, alongside representatives from the university.

But equally, the LangScape Curators project is designed to intersect with the emergent research carried out as part of the TLANG project. It aims to situate educational and public engagement with research as central to research processes, not as a post-project activity or an add-on. The research findings and the artistic products created by the young people are data in themselves, alongside the processes, which are also considered research. How can engagement work mirror the research itself and how can we find innovative ways to "bring the outside in', when it comes to our research? This concept is of particular relevance when we conduct ethnographic research, seeking to engage with people outside our institution.

The example here is one of the educational and public engagement activities developed from the TLANG project. It demonstrates how theoretical and methodological research frameworks can be developed within the context of languages engagement work. The activities developed for LangScape Curators are transdisciplinary and respond to key areas of the school curriculum: literacy, geography, history, art and, of course, languages. They encourage children and young people to become researchers themselves and to respond in an engaged and critical way to their environments. Returning to Ingold's metaphor, the traces of the research project are present and visible within the spaces of engagement, as meshworks. Although the focus is on the linguistic landscape, language (and certainly Language) is both centred and decentred. In using arts-based methods we also disrupt traditionally bounded ways of 'seeing' language (Berger, 1971) and ways of doing language research (Law, 2004; MacLure, 2013) and languages engagement.

\section{Conclusion}

This thought piece sought to bring research findings around translanguaging into dialogue with language engagement in higher education. I articulate some of the findings emerging from my research into translanguaging and dynamic multilingualism in community arts and street theatre and from the research into translanguaging across space and place in superdiverse cities. In describing some of the multiple and different ways in which translanguaging is being critiqued and extended, it aimed to set out the threads and traces of this work within the context of higher education languages engagement with children and young people. It was written in response to a range of questions emerging across the broader modern languages area which, following Michael Gratzke's (2017) statement for the 
University Council for Modern Languages (UCML), is understood as "a continuum of disciplines which cover Linguistics, Language Acquisition, Translation Studies, (languagebased) area studies, and (language-based) Humanities". Gratzke raises a number of important questions for the field as a whole, based around understandings of culture and its centrality within languages teaching and research. Like Gratzke's short piece, this article does not seek to answer all the questions it raises. But it does seek to make connections between the threads and traces which have not previously been articulated, namely how a dynamic multilingualism approach (from linguistics) might inform languages-focused engagement (in modern languages). It uses a brief example from a current transdisciplinary arts and language engagement project, LangScape Curators, to illustrate the possibilities and to make these connections, and as a translanguaging approach to engagement.

What might a translanguaging approach to language engagement look like? And how could translanguaging be adopted as epistemology in cross-sector, transdisciplinary languages engagement projects? Translanguaging offers a lens to consider the ways in which we draw from our communicative repertoires in daily life. A translanguaging approach to languages engagement might recognise:

1) we all draw from our communicative repertoires in different ways and across spaces and places;

2) we all bring multiple skills and experiences to interaction;

3) in working together we seek to develop and share our communicative resources, continually building on our own repertoires;

4) there are different ways of seeing (following John Berger, 1972): we make meaning in different ways and approaching from the perspective of different disciplines and fields strengthens our understandings;

5) commitment to collaboration and co-production (Facer \& Enright, 2016) in engagement work, starting from within universities themselves, and therefore drawing from across a wide range of disciplinary repertoires;

6) commitment to developing a repertoire of innovative research-based approaches to evaluation of such initiatives, building on but not limited to research methodologies in linguistic and visual ethnography.

There are significant methodological, epistemological and theoretical challenges to bringing together the diversity of approaches to language within the context of languages engagement. But, by seeking to work in a way which considers everyday multilingualism as 
normal and unremarkable (García \& Li Wei, 2014), with languages engagement programmes seeking to develop what Suresh Canagarajah (2013, p. 188) describes as a translingual orientation we can sketch out innovative approaches to languages engagement which foreground dynamic multilingualism.

This kind of approach aligns with what feminist economists J.K Gibson-Graham describe as a performative ontological project (Gibson-Graham, 2008) and which Anna Stetsenko calls a transformative activist stance (2015). Drawing from Law and Urry (2004, p. 391), Gibson-Graham (2008, p. 615) state that "to change our understanding is to change the world". In this way, this paper seeks to consider understandings of what languages engagement is and therefore what languages engagement might be. Now, with the uncertainty of Brexit, with the UK's decline in language take-up in schools and our increasingly tense relationship with Europe, new approaches to languages engagement are of vital importance.

\section{References}

Adami, E. (2017). Multimodality and superdiversity: Evidence for a research agenda. Tilbury Papers in Culture Studies, WP177. Retrieved from https://www.tilburguniversity.edu/research/institutes-and-researchgroups/babylon/tpcs/

Aden, J. (2013). Apprendre les langues par corps. In Abdlekader, S. B. \& Fertat, O. (Eds.), Pour un Théâtre-Monde - plurilinguisme, interculturalité, transmission (pp.109-123). Pessac: Presses universitaires de Bordeaux.

Atkinson, L., \& Bradley, J. (2017). Meaning making and collaborative ethnography in transdisciplinary arts. Working Papers in Translanguaging and Translation, WP23. Retrieved from http://www.birmingham.ac.uk/generic/tlang/publications/index.aspx

Badwan, K. (2015). Negotiating rates of exchange. Arab academic sojourners' sociolinguistic trajectories in the UK (Doctoral dissertation). University of Leeds, Leeds.

Baynham, M., Bradley, J., Callaghan, J., Hanusova, J., \& Simpson, J. (2015). Translanguaging business: unpredictability and precarity in superdiverse inner city Leeds. Working Papers in Translation and Translanguaging, WP4. Retrieved from http://www.birmingham.ac.uk/generic/tlang/working-papers/index.aspx

Baynham. M., \& Hanusova, J. (2017). On the relationality of centers, peripheries and interactional regimes: Translanguaging in a community interpreting event. AILA Review, 30, 144-166. DOI: https://doi.org/10.1075/aila.00007.bay 
Berger, J. (1972). Ways of Seeing. London: Penguin.

Blackledge, A., \& Creese, A. (2010). Multilingualism: A critical perspective. London: Continuum.

Blackledge, A., \& Creese, A. (2017). Translanguaging and the body. International Journal of Multilingualism, 14(3), 250-268. DOI: https://doi.org/10.1080/14790718.2017.1315809

Blackledge, A. \& Creese, A., with Baynham, M., Cooke, M., Goodson, L., Li Wei, Malkani, B., Phillimore, J., Robinson, M., Rock, F., Simpson, J., Tagg, C., Thompson, J., Trehan, K., and Zhu Hua. (2017). Language and superdiversity: An interdisciplinary perpsective. Working Papers in Translation and Translanguaging, WP26. Retrieved from http://www.birmingham.ac.uk/generic/tlang/index.aspx

Blommaert, J. (2013). Ethnography, superdiversity and linguistic landscapes: Chronicles of complexity. Bristol: Multilingual Matters.

Blommaert, J., \& Jie, D. (2010). Ethnographic fieldwork: A beginner's guide. Bristol: Multilingual Matters.

Bradley, J. (2015, June 16). Ethnographic fieldwork with an arts organisation: the betwixt and between [blog post]. from https://tlangblog.wordpress.com/2015/06/16/ethnographic-fieldwork-with-an-artsorganisation-the-betwixt-and-between-2/

Bradley, J. (2017). Liquid methodologies: Researching the ephemeral in multilingual street performance. In Conteh, J. (Ed), Researching education in multilingual settings (pp. 153-171). London: Bloomsbury.

Bradley, J. \& Moore, E. (forthcoming). Resemiotisation and creative production: Extending the translanguaging lens. In Adami, E., \& Sherris, A. (Eds), Making signs, translanguaging ethnographies: Exploring urban, rural, and educational spaces. Bristol: Multilingual Matters.

Bradley, J., Moore, E., Simpson, J., \& Atkinson, L. (2018). Translanguaging space and creative activity: Theorising collaborative arts-based learning. Language and Intercultural Communication, 18(1), 54-73. DOI: https://doi.org/10.1080/14708477.2017.1401120

Bradley, J., \& Simpson, J. (forthcoming). Negative translanguaging space: Mobility and immobility in inner-city Leeds. In Horner, K. \& J. Dailey-O'Cain (Eds.), Multilingualism and (im)mobilities: Language, power, agency. Bristol: Multilingual Matters. 
Busch, B. (2016). Methodology in biographical approaches in applied linguistics. Working Papers in Urban Language and Literacies, WP187. Retrieved from https://www.academia.edu/20211841/WP187_Busch_2016._Methodology_in_biograp hical approaches in applied linguistics

Callaghan, J., Moore, E., \& Simpson, J. (2018). Coordinated action, communication and creativity in basketball in superdiversity. Language and Intercultural Communication, 18(1), 28-53. DOI: https://doi.org/10.1080/14708477.2017.1401694

Canagarajah, S. (2011). Codemeshing in academic writing: Identifying teachable strategies of translanguaging. The Modern Language Journal, 95(3), 401-417. DOI: https://doi.org/10.1111/j.1540-4781.2011.01207.x

Canagarajah, S. (2013). Translingual practice: Global Englishes and cosmopolitan relations. London: Routledge. DOI: https://doi.org/10.4324/9780203073889

Collins, H. (2017). Unresolved tensions, hard realities and conflicting agendas: a review of the BAAL/Routledge Applied Linguistics workshop. Leeds Language Scholar Journal, 1, 1-6. Retrieved from https://languagescholar.leeds.ac.uk/wpcontent/uploads/sites/3/2017/05/Issue1-Collins.pdf

Cooke, M., \& Simpson, J. (2017). Recognising multilingual realities in ESOL. Language Issues, 28(2), 4-11.

Copeland, F. (1933). Zlatorog (A Slovene folk tale). The Slavonic and East European Review, 11(33), 651-654.

Copland, F., \& Creese, A. (2015). Linguistic ethnography: Collecting, analysing and presenting data. Los Angeles: SAGE. DOI: https://doi.org/10.4135/9781473910607

Creese, A., Takhi, J.K., \& Blackledge, A. (2014). Metacommentary in linguistic ethnography. In J. Snell, S. Shaw, \& F. Copland (Eds.), Linguistic ethnography: Interdisciplinary explorations (pp. 266-284). London: Palgrave Macmillian. DOI: https://doi.org/10.1057/9781137035035_14

Ding, A. (2016). Challenging scholarship: A thought piece. The Leeds Language Scholar Journal, 0, 6-18.

Eschenauer, S. (2014). Faire corps avec ces langues. Théâtre et didactique: vers une definition de la translangageance. Retrieved from https://www.academia.edu/7764540/Faire_corps_avec_ses_langues

Facer, K., \& B. Enright. (2016). Creating living knowledge: Connected communities and the participatory turn in the production of knowledge. Bristol: AHRC/UoB. Retrieved from http://www.connected-communities.org.uk 
Forsdick, C. (2017, February 23). Age cannot wither her, nor custom stale her infinite variety. Times Higher Education. Retrieved from https://www.timeshighereducation.com/features/do-we-need-modern-languagegraduates-in-globalised-world

García, O. (2009). Bilingual education in the 21st century: A global perspective. Malden, Mass; Chichester: Wiley-Blackwell.

García, O., \& Li Wei. (2014). Translanguaging: Language, bilingualism and education. Basingstoke: Palgrave Macmillan. DOI: https://doi.org/10.1057/9781137385765_4

Gibson-Graham, J.K. (2008). Diverse economies: Performative practices for other worlds. Progress in Human Geography. 32(5), 613-632. DOI: https://doi.org/10.1002/9781118384497.ch1

Halliday, M. A. K. (1978). Language as a social semiotic: Social interpretation of language and meaning. London: Edward Arnold.

Gorter, D., \& Cenoz, J. (2015). Translanguaging and linguistic landscapes. Linguistic Landscape, 1(1-2), 54-74.

Gratzke, M. (2017). Notes from UCML research workshop 30 June 2017. Retrieved from https://www.facebook.com/ucmluk/?hc ref=ARR4hpH2mzyQjOwSOI1Tz9So5 a8C Xf5cFt2No-GXapUrGA3RBZHv29jBeHaLFYXMU\&fref $=$ nf

Gumperz, J. J. (1982). Discourse strategies. Cambridge: Cambridge University Press. DOI: https://doi.org/10.1017/cbo9780511611834

Harvey, L. (2016). I am Italian in the world": A mobile student's story of language learning and ideological becoming. Language and Intercultural Communication, 16(3), 368383. DOI: https://doi.org/10.1080/14708477.2016.1168049

Hutchings, S., \& Matras, Y. (2017, June 14). Modern linguists must craft their own reforms to reclaim the future of their discipline. Cross Language Dynamics. Retrieved from http://projects.alc.manchester.ac.uk/cross-language-dynamics/modern-linguists-mustcraft-reforms-reclaim-future-discipline-2/

Hymes, D. (1972). On communicative competence. In J. B. Pride, \& J. Holmes (Eds.), Sociolinguistics (pp. 269-293). Harmondsworth: Penguin.

Hymes, D. (1974). Foundations in sociolinguistics: An ethnographic approach. Philadelphia: University of Pennsylvania Press.

Iedema, R. (2001). Resemiotization. Semiotica, 37(1/4), 23-40. DOI: https://doi.org/10.1515/semi.2001.106 
Iedema, R. (2003). Multimodality, resemiotization: Extending the analysis of discourse as multi-semiotic practice. Visual Communication, 2(1), 29-57. DOI: https://doi.org/10.1177/1470357203002001751

Ingold, T. (2016/2007). Lines. A brief history. London: Routledge. DOI: https://doi.org/10.4324/9781315625324

Jaspers, J. (2017). The transformative limits of translanguaging. Working Papers in Urban Language and Literacies, WP226. Retrieved from https://www.academia.edu/34532582/WP226 Jaspers 2017. The transformative lim its_of translanguaging

Jewitt, C., Bezemer, J., \& O’Halloran, K. (2016). Introducing multimodality. London: Routledge. DOI: https://doi.org/10.4324/9781315638027

Jørgenson, (2008). Polylingual languaging around and among children and adolescents. International Journal of Multilingualism, 5(3), 161-176. DOI: https://doi.org/10.1080/14790710802387562

Kell, C. (2015). 'Making people happen': Materiality and movement in meaning-making trajectories. Social Semiotics, 25(4), 423-445. DOI: https://doi.org/10.1080/10350330.2015.1060666

Kress, G. (2011). 'Partnerships in research': Multimodality and ethnography. Qualitative Research, 11(3), 239-260. DOI: https://doi.org/10.1177/1468794111399836

Kress, G., \& van Leewen, T. (1996). Reading images: The grammar of visual design. London: Routledge.

Kress, G., \& van Leeuwen, T. (2001). Multimodal discourse: The modes and media of contemporary communication. New York: Oxford University Press.

Kusters, A., Spotti, M., Swanwick, R. \& Tapio, E. (2017). Beyond languages, beyond modalities: transforming the study of semiotic repertoires. International Journal of Multilingualism, 14(3), 219-232. DOI: https://doi.org/10.1080/14790718.2017.1321651

Lanvers, U. (2011). Language education policy in England. Is English the elephant in the room? Apples - Journal of Applied Language Studies, 5(3), 63-78.

Lanvers, U. \& Coleman, (2017). The UK language learning crisis in the public media: a critical analysis. The Language Learning Journal, 45(1), 3-25. DOI: https://doi.org/10.1080/09571736.2013.830639

Law, J., \& Urry, J. (2004). Enacting the social. Economy and Society, 33, 390-410. 
Lefebvre, H. (1991/1974). The production of space. Oxford: Blackwell.

Li Wei (2011). Moment Analysis and translanguaging space: Discursive construction of identities by multilingual Chinese youth in Britain. Journal of Pragmatics, 43(5), 1222-1235. DOI: https://doi.org/10.1016/j.pragma.2010.07.035

Lüdi, G., \& Py, B. (2009). To be or not to be ... a plurilingual speaker. International Journal of Multilingualism, 6(2), 154-167. DOI: https://doi.org/10.1080/14790710902846715

MacLure, M. (2013). Researching without representation? Language and materiality in postqualitative methodology. International Journal of Qualitative Studies in Education, 26(6), 658-667. DOI: https://doi.org/10.1080/09518398.2013.788755

MacSwan, J. (2017). A multilingual perspective on translanguaging. American Educational Research Journal, 54(1), 167-201. DOI: https://doi.org/10.3102/0002831216683935

Makoni, S., \& Pennycook, A. (Eds) (2007). Disinventing and reconstituting languages. Bristol: Multilingual Matters.

McKay, S., \& Bradley, J. (2016). How does arts practice engage with narratives of migration from refugees? Lessons from 'utopia'. Journal of Arts and Communities, Special Edition with Amnesty International on Arts, Activism and Human Rights, 8(1-2), 3146. DOI: https://doi.org/10.1386/jaac.8.1-2.31_1

Moore, E., Bradley, J., \& Simpson, J. (Eds.) (forthcoming). Translanguaging as transformation: The collaborative construction of new linguistic realities. Clevedon: Multilingual Matters.

Otheguy, R., García, O., \& Reid, W. (2015). Clarifying translanguaging and deconstructing named languages: A perspective from linguistics. Applied Linguistics Review, 6(3), 281-307. DOI: https://doi.org/10.1515/applirev-2015-0014

Otsuji, E., \& Pennycook, A. (2010). Metrolingualism: Fixity, fluidity and language in flux. International Journal of Multilingualism, 7(3), 240-254. DOI: https://doi.org/10.1080/14790710903414331

Pennycook, A. (2017). Translanguaging and semiotic assemblages. International Journal of Multilingualism, 14(3), 269-282.

DOI: https://doi.org/10.1080/14790718.2017.1315810

Pennycook, A. \& Otsuji, E. (2015). Metrolingualism: Language in the city. Oxon: Routledge. DOI: https://doi.org/10.4324/9781315724225

Perriam, C. (2017, July 2). Comment on "Modern Linguists must craft their own reforms to reclaim the future of the discipline". Cross Language Dynamics. Retrieved from 
http://projects.alc.manchester.ac.uk/cross-language-dynamics/comment-modernlinguists-must-craft-reforms-reclaim-future-discipline/

Pink, S. (2011). Multimodality, multisensoriality and ethnographic knowing: Social semiotics and the phenomenology of perception. Qualitative Research, 11(3), 261-276. DOI: https://doi.org/10.1177/1468794111399835

Pink, S. (2014). Doing visual ethnography. London: SAGE.

Pink, S. \& Morgan, J. (2013). Short-term ethnography: Intense routes to knowing. Symbolic Interaction, 36(3), 351-361. DOI: https://doi.org/10.1002/symb.66

Pratt, M.L. (1991). Arts of the contact zone. Profession, 33-40.

Rowsell, J. (2012). Working with multimodality: Rethinking literacy in a digital age. Abingdon: Routledge. DOI: https://doi.org/10.4324/9780203071953

Rymes, B. (2013). Communicating beyond language. New York: Routledge. DOI: https://doi.org/10.4324/9780203129616

Scollon, R., \& Scollon, S. W. (2004). Nexus analysis: Discourse and the emerging internet. London: Routledge. DOI: https://doi.org/10.4324/9780203694343

Simpson, J. \& Bradley, J. (2017). Communication in the contact zone: The TLANG project and ESOL. Language Issues, 27(2), 4-18.

Stetsenko, A. (2015). Theory for and as social practice of realizing the future implications from a transformative activist stance. In J. Martin, J. Sugarman, \& K. L. Slaney (Eds.), The Wiley handbook of theoretical and philosophical psychology: Methods, approaches, and new directions for social sciences (pp. 102 - 116). Malden, MA: John Wiley \& Sons. DOI: https://doi.org/10.1002/9781118748213.ch7

Zhu Hua, Li Wei \& Lyons, A. (2017). Polish shop(ping) as translanguaging space. Journal of Social Semiotics, 27(4), 411-433. DOI: https://doi.org/10.1080/10350330.2017.1334390

\footnotetext{
Author Information:

Jessica Bradley is an applied linguist and educational researcher, with research interests in outreach and engagement, social justice, professional language use, arts-based contexts, and cross-sector collaboration. She has over thirteen years' experience of designing, delivering and evaluating cross-sector engagement programmes and activities in higher education engagement at the University of Leeds and Leeds Trinity University. Her doctoral research is part of the AHRC-funded 'TLANG' Project and based in the School of Education at the University of Leeds. She is Lecturer in Education in the Institute of Childhood and Education at Leeds Trinity University.

Email: j.bradley@leedstrinity.ac.uk
} 
To cite this article:

Bradley, J. (2017). Translanguaging engagement: Dynamic multilingualism and university language engagement programmes. Bellaterra Journal of Teaching \& Learning Language \& Literature, 10(4), 9-31. DOI: https://doi.org/10.5565/rev/jt13.759

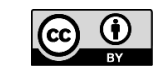

\footnotetext{
i There are also two more categories of lines according to Ingold's taxonomy. These are 'the cut, the crack and the crease' which form by 'ruptures in the surfaces themselves' (2016:46) and 'ghostly lines' which he uses to describe lines which are 'visionary or metaphysical' (p.50).

${ }^{i i}$ Arts and Humanities Research Council (1/4/2014-31/3/2018) 'Translation and Translanguaging. Investigating Linguistic and Cultural Transformations in Superdiverse Wards in Four UK Cities' ((AH/L007096/1), $£ 1,973,527)$, Principal Investigator: Angela Creese, with Mike Baynham, Adrian Blackledge, Jessica Bradley, John Callaghan, Lisa Goodson, Ian Grosvenor, Amal Hallak, Jolana Hanusova, Rachel Hu, Daria JankowiczPytel, Agnieszka Lyons , Bharat Malkani, Sarah Martin, Emilee Moore, Li Wei, Jenny Phillimore, Mike Robinson, Frances Rock, James Simpson, Jaspreet Kaur Takhi, Caroline Tagg, Janice Thompson, Kiran Trehan, Piotr Wegorowski, and Zhu Hua.

iii See www.routesintolanguages.ac.uk (accessed 4 August 2017).

${ }^{\text {iv }}$ See https://www.britishcouncil.org/education/schools/support-for-languages/thought-leadership/researchreport/language-trends-2016-17 (accessed 4 August 2017).

${ }^{v}$ See http://blog.hefce.ac.uk/2017/04/03/an-experimental-approach-to-evaluate-the-impact-of-outreach/ (accessed 4 August 2017).

${ }^{v i}$ See https://www.britishcouncil.org/education/schools/support-for-languages/thoughtleadership/appg/news/brexit-languages (accessed 4 August 2017).

${ }^{\text {vii }}$ See

https://www.leeds.ac.uk/arts/info/20043/school of languages cultures and societies/2838/resources for schoo 1 languages teachers (accessed 4 August 2017).

viii See http://www.ucml.ac.uk/news/302 (accessed 4 August 2017).

${ }^{\text {ix }}$ See www.langscapecurators.tumblr.com (accessed 4 August 2017).
} 